\title{
Multi-point ground-based ULF magnetic field observations in Europe during seismic active periods in 2004 and 2005
}

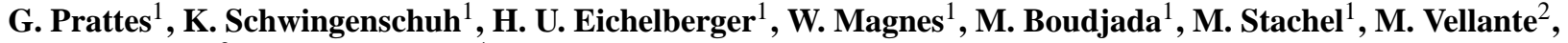 \\ V. Wesztergom ${ }^{3}$, and P. Nenovski ${ }^{4}$ \\ ${ }^{1}$ Institut für Weltraumforschung, Österreichische Akademie der Wissenschaften (IWF/ÖAW), Graz, Austria \\ ${ }^{2}$ Dipartimento di Fisica, Università dell'Aquila, L'Aquila, Italy \\ ${ }^{3}$ Geodetic and Geophysical Research Institute of the Hungarian Academy of Science, Sopron, Hungary \\ ${ }^{4}$ Geophysical Institute, Sofia, Bulgaria
}

Received: 26 February 2008 - Revised: 7 May 2008 - Accepted: 7 May 2008 - Published: 16 May 2008

\begin{abstract}
We present the results of ground-based Ultra Low Frequency (ULF) magnetic field measurements observed from June to August 2004 during the Bovec earthquake on 12 July 2004. Further we give information about the seismic activity in the local observatory region for an extended time span 2004 and 2005. ULF magnetic field data are provided by the South European Geomagnetic Array (SEGMA) where the experience and heritage from the CHInese MAGnetometer (CHIMAG) fluxgate magnetometer comes to application. The intensities of the horizontal $H$ and vertical $Z$ magnetic field and the polarization ratio $R$ of the vertical and horizontal magnetic field intensity are analyzed taking into consideration three SEGMA observatories located at different close distances and directions from the earthquake epicenter. We observed a significant increase of high polarization ratios during strong seismic activity at the observatory nearest to the Bovec earthquake epicenter. Apart from indirect ionospheric effects electromagnetic noise could be emitted in the lithosphere due to tectonic effects in the earthquake focus region causing anomalies of the vertical magnetic field intensity. Assuming that the measured vertical magnetic field intensities are of lithospheric origin, we roughly estimate the amplitude of electromagnetic noise in the Earths crust considering an average electrical conductivity of $<\sigma>=10^{-3} \mathrm{~S} / \mathrm{m}$ and a certain distance of the observatory to the earthquake epicenter.
\end{abstract}

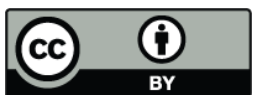

Correspondence to: G. Prattes (gustav.prattes@oeaw.ac.at)

\section{Introduction}

At the beginning the instrumental characteristics of the magnetometers are described and an overview about the seismic activity during this epoch is given. It is suggested by many authors performing ULF seismic observations (Fraser-Smith et al., 1990; Hayakawa and Fujinawa, 1994; Hayakawa et al., 1996, 2007; Molchanov et al., 2002, 2004b; Kopytenko et al., 2004; Harada et al., 2004; Sorokin et al., 2004) to apply certain standard signal processing methods to magnetic field data to possibly extract seismogenic electromagnetic ULF emission.

\subsection{Instrument and data base}

The CHIMAG fluxgate magnetometer was originally developed at the Space Research Institute of the Austrian Academy of Sciences Graz, to investigate magnetic pulsations in the ULF range. The vital parameters of the high temporal resolution 3-axes fluxgate magnetometer are the measurement range of $\pm 512 \mathrm{nT}$, the compensation field of $60000 \mathrm{nT}$ in $\mathrm{X}$ and $\mathrm{Z}$ and $\pm 30000 \mathrm{nT}$ in $\mathrm{Y}$ direction. The accuracy is $8 \mathrm{pT}$ at a temporal resolution of $1 \mathrm{~Hz}$, derived from the highest possible sampling frequency of $64 \mathrm{~Hz}$. The 3 -axes magnetometer measures in $\mathrm{X}$ (positive Northward), $\mathrm{Y}$ (positive Eastward) and Z (positive towards the centre of the Earth) direction (Magnes, 1999; Schwingenshuh et al., 2000). The CHIMAG magnetometer comes to application in the frame of the SEGMA project, see Vellante et al. (2004). Figure 1 shows by yellow markers the SEGMA observatories Castello Tesino (CST), Ranchio (RNC), both Italy and Nagycenk (NCK), Hungary, which are evaluated in the frame of this work. The stations L'Aquila, Italy and Panagyurishte, Bulgaria (shown by white markers) belong to the SEGMA

Published by Copernicus Publications on behalf of the European Geosciences Union. 
Table 1. Geographic coordinates of SEGMA stations and corresponding distances to the Bovec earthquake epicenter.

\begin{tabular}{ccccc}
\hline Station & \multicolumn{3}{c}{ Geographic Coordinates } & Distance to \\
\cline { 1 - 3 } Name & Code & Lat. $\left[{ }^{\circ} \mathrm{N}\right]$ & Long. $\left[{ }^{\circ} \mathrm{E}\right]$ & Bovec $[\mathrm{km}]$ \\
\hline Castello Tesino & CST & 46.0 & 11.7 & 153 \\
Nagycenk & NCK & 47.6 & 16.7 & 275 \\
Ranchio & RNC & 43.97 & 12.08 & 291 \\
\hline
\end{tabular}

chain but are not contributing to this work. The Bovec earthquake happened on the 12 July 2004, with magnitude $M=5.5$ at a depth of $h \sim 6 \mathrm{~km}$. The Bovec earthquake epicenter is indicated with the red marker in Fig. 1. One can see in Table 1 that the closest SEGMA station to the epicenter is Castello Tesino at a distance of $153 \mathrm{~km}$, Nagycenk station is located at $275 \mathrm{~km}$ and Ranchio observatory is at $291 \mathrm{~km}$ distance. The Zentrale Anstalt für Meteorologie und Geodynamik (ZAMG, 2007) reported about damage of more than 1100 houses in the epicenter region. Several walkers where hurt because of rock fall, reportedly one person lost his life. In far parts of Austria ground motion was observed and houses in Carinthia were damaged. Even in Vienna vibrations were noticed. Table 1 shows the SEGMA stations with geographic coordinates and the distance to the Bovec earthquake epicenter.

\subsection{Seismic events}

To find a possible connection between an earthquake and magnetic field ULF signatures as precursor candidates, (Gladychev et al., 2001) introduced the so-called seismic in$\operatorname{dex} K_{s}$. They found the following empirical relation

$K_{s}=K_{t h} \cdot \frac{10^{0.75 \cdot M s}}{10 \cdot R} \cdot\left(1+R \cdot 10^{-\frac{M s}{2}}\right)^{-2.33}$,

where $K_{t h}$ is a threshold value, $M_{s}$ is the magnitude of the earthquake and $R$ is the distance between the earthquake and the observatory. The seismic index $K_{s}$ for the Bovec earthquake on 12 July 2004 for Castello Tesino observatory is $K_{S C S T}=7.8$, for Nagycenk $K_{S N C K}=3.2$ and for Ranchio $K_{S R N C}=3.1$.

Apart from the Bovec earthquake several seismic events happened in the local area of the SEGMA observatories in the two year time period 2004/2005. Table 2 shows date, geographic coordinates and magnitude of these seismic events. Also in this table the distance to the closest SEGMA station, the earthquake focus depth and the concerning station as well as the seismic index Ks are listed.

The listed events were analysed in Prattes (2007). The event oriented analysis showed a weak correlation between the earthquake magnitude and the strength of emitted electromagnetic noise.

\section{Scientific background and methodology}

Experience showed that night time magnetic field data are less influenced by man made and geomagnetic effects than day time hours. We extracted the local midnight period from 22:00 LT-02:00 LT (UT+1) for further analysis and divided this $4 \mathrm{~h}$ period into 8 half hour intervals equally distributed, 30 min each. Each of these segments was subjected to a FFT analysis taking into consideration data processing rules. The selected sampling frequency is $f_{S}=1 \mathrm{~Hz}$ so the upper analyzable frequency is $f_{N Y}=f_{S} / 2=500 \mathrm{mHz}$. The frequency response of the horizontal and vertical magnetic field component was separated into three sub bands, $10-50 \mathrm{mHz}, 50$ $100 \mathrm{mHz}$ and $100-450 \mathrm{mHz}$. In the frame of this work we focus on the lower frequency band from $10-50 \mathrm{mHz}$ because of the highest $\mathrm{S} / \mathrm{N}$ ratio. Further the power spectral density $S$ was determined

$S_{Z}(f)=\frac{\left|B_{Z}(f)\right|^{2}}{\Delta f}, S_{H}(f)=\frac{\left|B_{H}(f)\right|^{2}}{\Delta f}$,

where $B(f)$ is the frequency response and $\Delta f$ is the selected bandwidth which is $40 \mathrm{mHz}$ in the frequency span from 10 $50 \mathrm{mHz}$.

Continuing the calculations lead to the monthly mean and standard deviation for both components and every sub band. Comparisons between certain day and half hour magnetic field intensities to the monthly mean plus standard deviation help to estimate the wave intensity. The geomagnetic condition is expressed in $\Sigma K_{p}$ values. Strong geomagnetic influence expressed in high $\Sigma K_{p}$ values manifests in strong magnetic field intensities. Geomagnetic pulsations during night time are usually $H$ polarized, typically measurable in the Pc4 band (period close to $100 \mathrm{~s}$ ). We expect high variations in the intensities of the magnetic field components during strong geomagnetic influence. The $\Sigma K_{p}$ values were taken from The International Service of Geomagnetic Indices (ISGI, 2007).

By summing up we evaluate a certain value for the wave intensity in half hour segments for the vertical and horizontal field component. A key parameter in non seismic earthquake analysis is the polarization ratio $R$, see also Hayakawa et al. (1996) or Molchanov et al. (2002, 2004b), which is defined as the vertical over the horizontal magnetic field power.

$R=\frac{S_{Z}}{S_{H}}$,

where $S_{Z}$ and $S_{H}$ are the magnetic field intensities of the vertical and the horizontal component in the frequency band from $10-50 \mathrm{mHz}$. This proxy value is expected to be high $(R>1)$ before and during strong seismic activity.

The reason for high ratios can be an increased vertical magnetic field power which can be associated to direct mechanisms acting in the crust, so-called microfracture electrification (Molchanov and Hayakawa, 1998), as sketched in Fig. 3. Another possibility for a high polarization ratio is a 


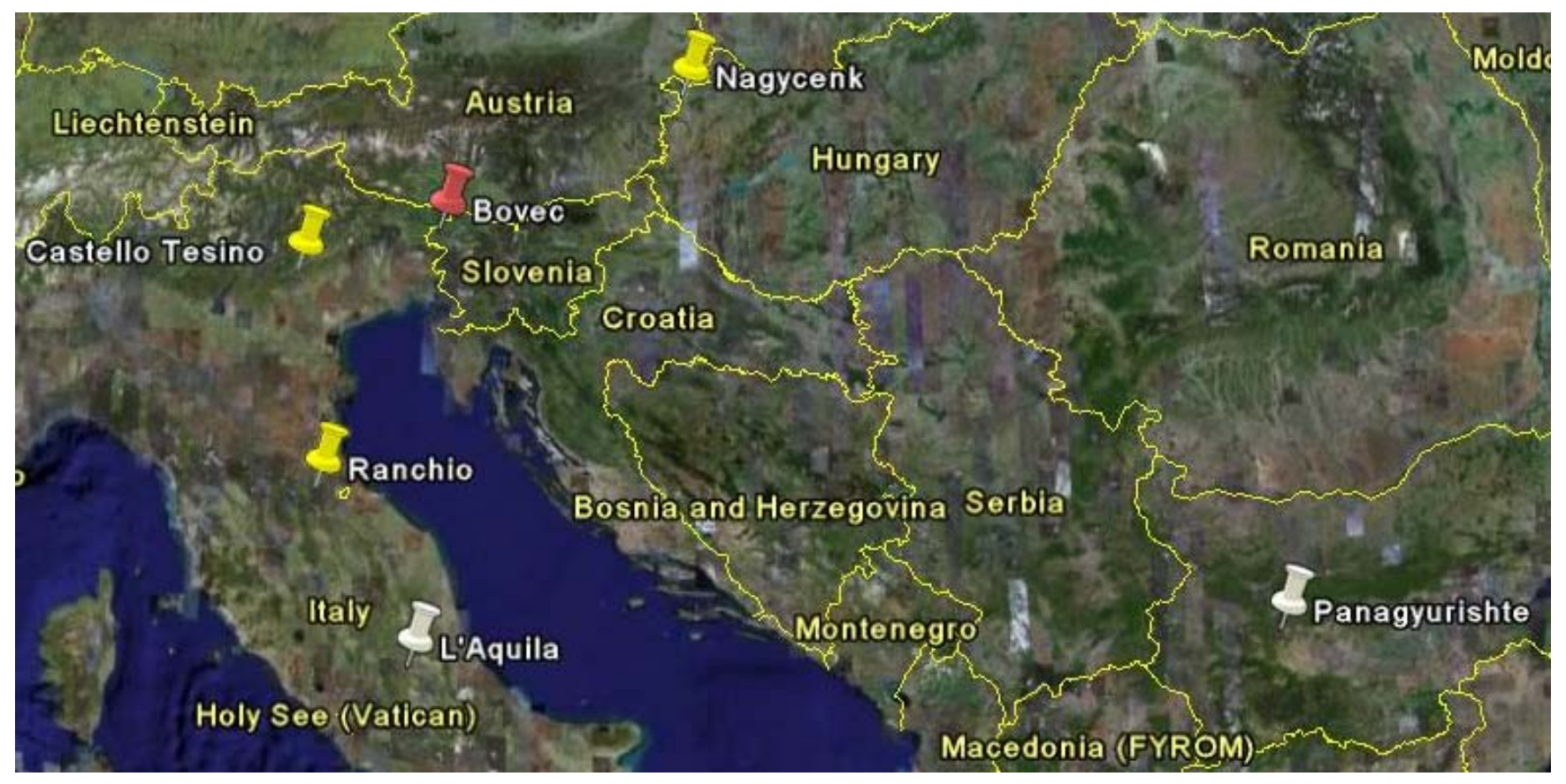

Fig. 1. SEGMA stations and the Bovec earthquake epicenter (Google Earth).

Table 2. Seismic events of interest during 2004 and 2005 for the SEGMA stations CST, RNC and NCK.

\begin{tabular}{|c|c|c|c|c|c|c|c|}
\hline Event date & \multicolumn{2}{|c|}{ Geographic Coord. } & Intensity & Distance to station $[\mathrm{km}]$ & Depth of focus $[\mathrm{km}]$ & Station & $K_{S}$ \\
\hline 29 Aug 2004 & $46.40^{\circ} \mathrm{N}$ & $12.88^{\circ} \mathrm{E}$ & 4.3 & 101 & 10 & CST & 0.48 \\
\hline 10 Jun 2004 & $44.02^{\circ} \mathrm{N}$ & $12.01^{\circ} \mathrm{E}$ & 2.6 & 8 & 38 & RNC & 0.50 \\
\hline 29 Aug 2004 & $43.87^{\circ} \mathrm{N}$ & $11.96^{\circ} \mathrm{E}$ & 3.00 & 14 & 7 & & 0.54 \\
\hline 28 Jun 2004 & $47.6^{\circ} \mathrm{N}$ & $16.45^{\circ} \mathrm{E}$ & 3.2 & 18 & 5 & NCK & 0.58 \\
\hline Event date & \multicolumn{2}{|c|}{ Geographic Coord. } & Intensity & Distance to station $[\mathrm{km}]$ & Depth of focus $[\mathrm{km}]$ & Station & $K_{S}$ \\
\hline $25 \mathrm{Jul} 2005$ & $47.81^{\circ} \mathrm{N}$ & $16.28^{\circ} \mathrm{E}$ & 4.1 & 38 & 12 & NCK & 1.58 \\
\hline 15 Jul 2005 & $44.20^{\circ} \mathrm{N}$ & $12.09^{\circ} \mathrm{E}$ & 3 & 25 & 19 & & 0.18 \\
\hline $15 \mathrm{Jul} 2005$ & $44.21^{\circ} \mathrm{N}$ & $12.12^{\circ} \mathrm{E}$ & 4.8 & 26 & 22 & $\mathrm{RNC}$ & 12.17 \\
\hline $15 \mathrm{Jul} 2005$ & $44.22^{\circ} \mathrm{N}$ & $12.10^{\circ} \mathrm{E}$ & 4.0 & 28 & 22 & & 2.00 \\
\hline $15 \mathrm{Jul} 2005$ & $44.20^{\circ} \mathrm{N}$ & $12.09^{\circ} \mathrm{E}$ & 3.0 & 25 & 21 & & 0.18 \\
\hline
\end{tabular}

decrease of the horizontal magnetic field power which can be related to indirect mechanisms like lithosphere-atmosphereionosphere coupling effects, see Gokhberg et al. (1995), Molchanov et al. (2004a), Sorokin et al. (2004), Parrot et al. (2006) and Biagi et al. (2007). Hot water and gas release in the earthquake epicenter region leads to Atmospheric Gravity Waves (AGW's) causing turbulence in the lower ionosphere between $80 \mathrm{~km}$ and $120 \mathrm{~km}$ altitude as seen in Fig. 2. A down-propagating Alfvén wave from the magnetosphere causes a depression of the ULF horizontal magnetic field component on the ground. One further effect called inductive seismo-electromagnetic effect was described by Molchanov et al. (2001). The two possible generation mechanisms of ULF anomalies on the surface are sketched in 


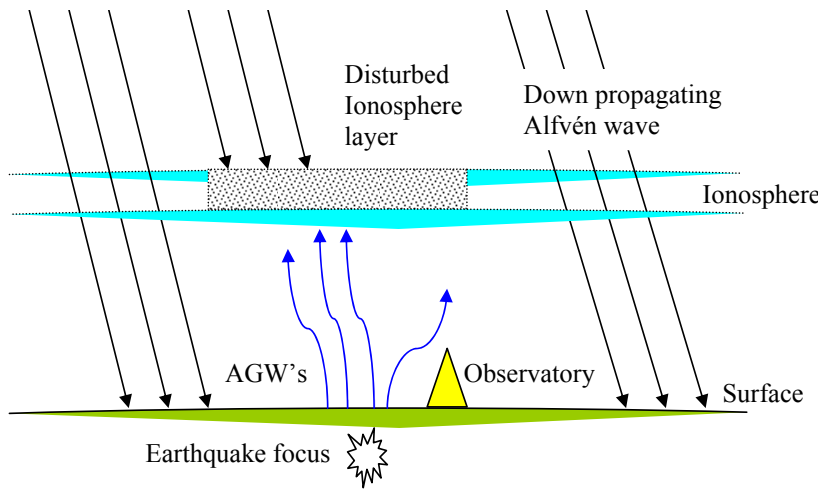

Fig. 2. Sketch of possible ULF anomalies related to earthquakes due to lithosphere ionosphere coupling.

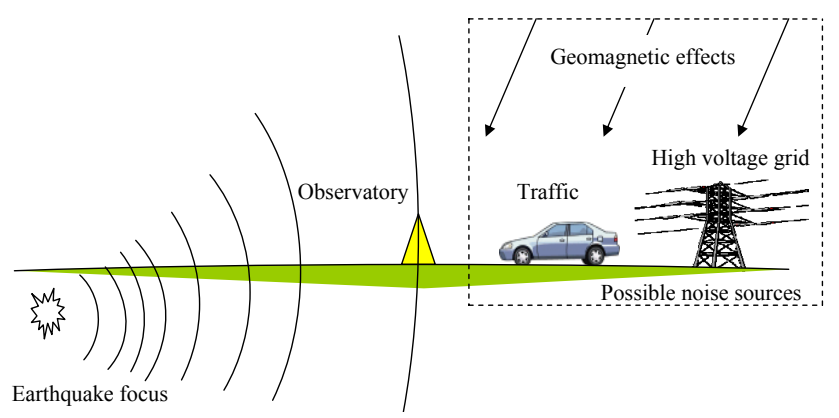

Fig. 3. Sketch of possible ULF anomalies related to earthquakes due to direct lithospheric electromagnetic emission and possible natural and artificial noise sources.

Figs. 2 and 3. In Fig. 3 the possible noise emission sources are shown. Apart from seismogenic noise emission, noise is due to (i) artificial emissions e.g. traffic or any moving magnetic object or the high voltage grid and (ii) geomagnetic effects. To sort out the source of noise emissions geomagnetic effects represent the strongest influence followed by man made emission. Many authors reported about the importance and difficulties of discriminating man made noise, e.g. Harada et al. (2004), Villante et al. (2004) and Masci et al. (2007). Less influence due to man made noise is expected during the nighttime hours which is the reason why we selected the local midnight time period for detailed analysis as described in Sect. 2. Man made noise can be mainly observed in the vertical magnetic field component. Electromagnetic emission due to processes in the lithosphere like microfracture electrification causes anomalies in vertical direction too. Multi-point investigation help to identify artificial noise from a certain station. We benefit from the SEGMA chain measurements and compared vertical magnetic field intensities from CST, RNC and NCK to determine the data quality of the stations and found the highest noise level at CST station, followed by RNC and NCK. To distinguish man made noise from seismogenic emission sophisticated signal processing methods have to be applied.
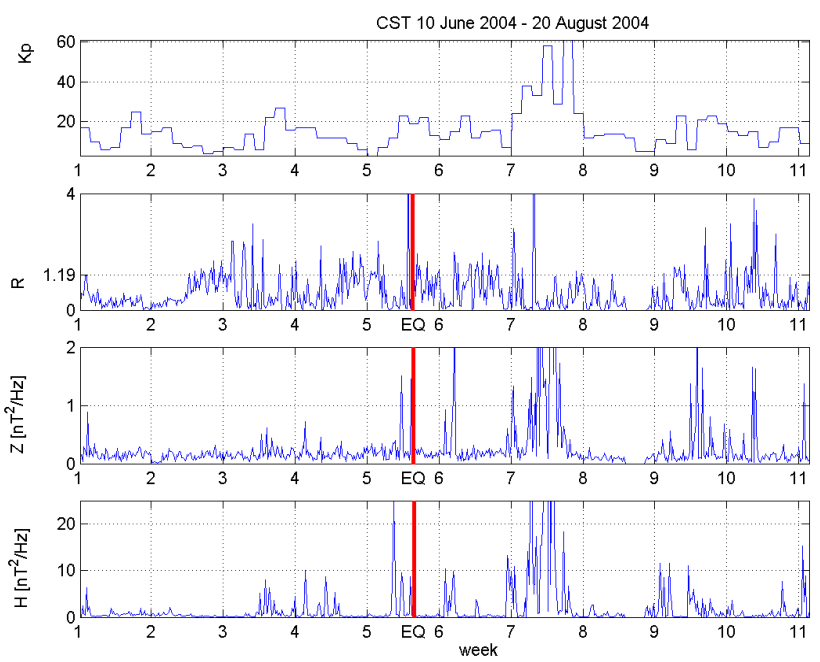

Fig. 4. Temporal evolution of geomagnetic index $\Sigma K_{p}$, polarization $R, Z$-intensity and $H$-intensity from 10 June to 20 August 2004 measured at CST station during nighttime. The red vertical line indicates the occurrence time of the earthquake.

\section{Analysis of seismomagnetic events}

In this section polarization analysis results are presented for the 10 week period from 10 June 2004 to 20 August 2004. Three different SEGMA stations CST, RNC and NCK were taken into account. An estimation of the possible magnetic field strength variation in the Bovec earthquake focus region is determined.

\subsection{Polarization analysis}

In Fig. 4 the temporal evolution of $\Sigma K_{p}$, the polarization ratio $R$ and the intensity of the $Z$ and $H$ components during the ten week long period from 10 June to 20 August 2004 are shown measured at CST station. Every frequency response segment (eight values correspond to one day) is summed to estimate a certain value for the field intensity and concatenated for the whole time period. The Bovec earthquake on 12 July 2004 is indicated with EQ and a red line in week 5. By analysing the single component intensities one can see that during strong geomagnetic activity in week seven, the wave intensities are high for both single components. The intensity increase of the horizontal component dominates compared to the increase of the vertical intensity leading to small polarization ratios during week seven. The increase of $R$ shown in panel two during week two and three which was around three weeks before the earthquake could be due to a decrease of the horizontal intensity. The temporal evolution of the vertical component does not show any obvious increase during this time period. The increase of $R$ during the end of week four and the beginning of week five is due to similar effects. A clear enhancement of $R$ on 12 July 2004 is due to high 
空
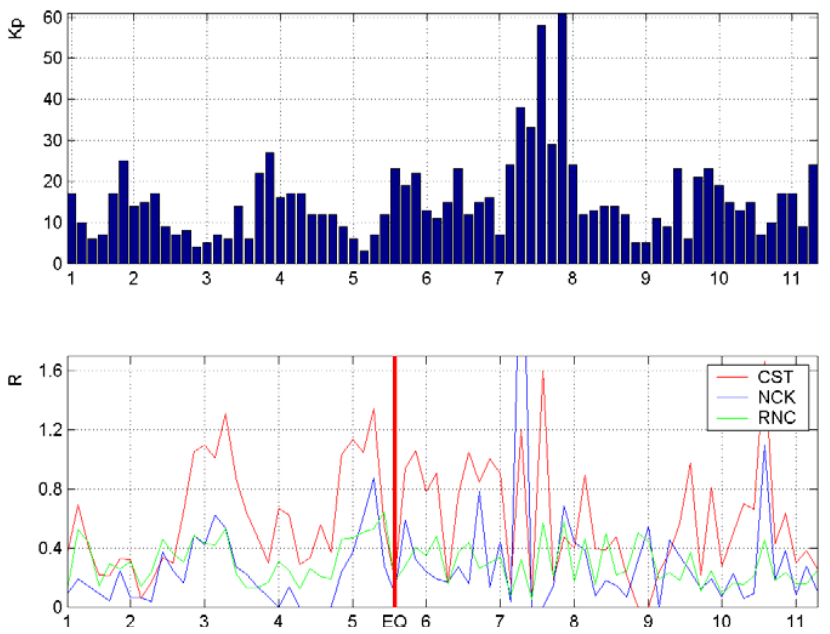

Fig. 5. Panel 1: $\Sigma K_{p}$ value, Panel 2: Temporal evolution of $R$ measured at Castello Tesino (red), Nagycenk (blue) and Ranchio (green) stations for an averaging period of one day.

vertical magnetic field intensity. During week five both magnetic field component intensities are increased.

Figure 5 shows the $\Sigma K_{p}$ value representing the geomagnetic condition in the upper panel. The lower panel shows the temporal evolution of $R$ for the SEGMA stations CST, NCK and RNC for one day averaging. The highest ratios can be observed at Castello Tesino. One can see significant changes at the end of week two and during week four and week five, short before the Bovec earthquake indicated with label EQ and a red line in week 5. In week seven the geomagnetic activity was strong enough to cause fast changes in the polarization ratio determined at Nagycenk and Castello Tesino station.

The polarization mean plus standard deviation at CST station for the ten week period is 1.19 indicated in the second panel of Fig. 4. For NCK station mean plus standard deviation was 1.31, and for RNC station it was 0.61 .

The mean plus sigma of $R$ exceeded the threshold 85 times in the whole observed time period at CST station, 13 times in week three, 11 times in week four, 12 times in week five and 15 times in week 6 . A majority of polarization enhancement happened before during and short after the Bovec earthquake in week 5. At the SEGMA stations Ranchio (RNC) the polarization ratio value of 0.61 was exceeded 53 times in the ten week long time period. At Nagycenk (NCK) station the polarization raised above 1.3124 times in the ten week long period of interest. Figure 6 shows a station comparison of polarization enhancement, the blue bar shows Nagycenk, the green bar Ranchio and the red bar Castello Tesino station. The Bovec earthquake happened during week 5 . The number of enhanced polarization values is much higher at CST station which was the closest SEGMA station to the epicenter compared to NCK and RNC. During week four the number of high polarization values was zero, during week five it was

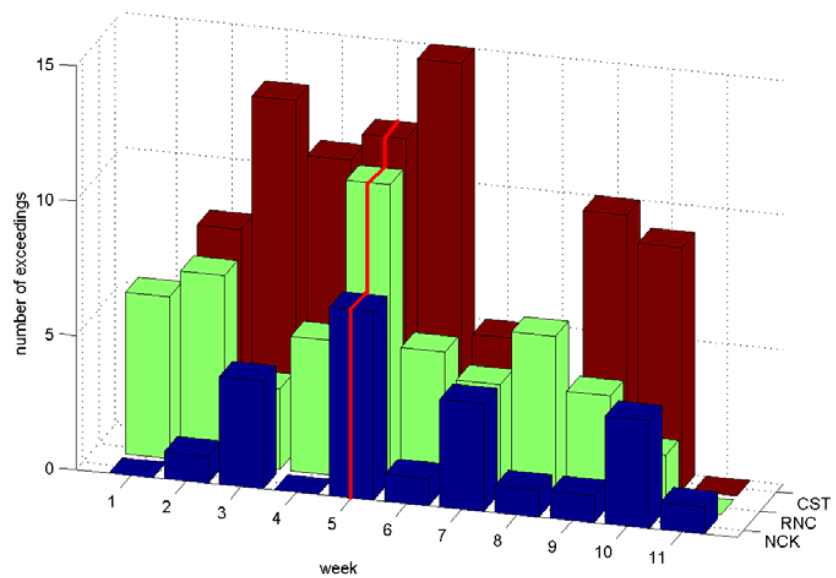

Fig. 6. Station comparison of polarization enhancement.

seven, during week six it was one at NCK. At RNC station the number of high polarization values in week four was five, during week five ten and during week six it was five. A common significant enhancement of polarization at all stations CST, NCK and RNC can be observed during week five.

\subsection{Estimation of the electromagnetic field in the earth- quake focus}

The majority of earthquake focuses are distributed between the surface and depths of about $70 \mathrm{~km}$. We assume that a source emitting wideband electromagnetic noise is located in the hypocenter dissipating the energy outside the source region. High frequency components are attenuated very strong, having low skin depths, whereas lower frequencies penetrate the Earth's lithosphere without significant attenuation. The probability of earthquake signature manifestation is much higher in the ULF frequency range than in other frequencies. The following Table 3 shows the averaged electrical conductivity $<\sigma>$ for different materials and the corresponding skin depths $\delta$ evaluated at certain low frequencies.

During geomagnetic quiet periods from 19 June 2004 to 27 June 2004 an example of vertical magnetic field power increase exceeding the monthly mean plus standard deviation is shown under the condition that the polarization ratio $R$ is high $(R>1)$ on 24 June 2004. Measurements were taken from the SEGMA station Castello Tesino (CST).

In the frequency range from $10-50 \mathrm{mHz}$ the eight half hour segments showed a maximum vertical intensity variation from 22:30-23:00 (UT+1) which was $\delta Z_{\max }=0.157 \mathrm{nT}$. If we assume that this measured anomaly is a precursor of the Bovec earthquake we can roughly estimate the intensity in the earthquake focus region. Therefore we have to think of an electromagnetic wave propagating through an electrical conductive lithosphere. The earthquake focus lies in a depth of $h \sim 6 \mathrm{~km}$ which is negligible compared to the distance of $d=153 \mathrm{~km}$ to Castello Tesino station $(h \ll d)$. The skin depth 
Table 3. Electrical conductivity and skin depth for different materials at certain frequencies.

\begin{tabular}{lllll}
\hline Material & $<\sigma>[\mathrm{S} / \mathrm{m}]$ & $\delta_{10 \mathrm{mHz}}[\mathrm{m}]$ & $\Delta_{100 \mathrm{mHz}}[\mathrm{m}]$ & $\delta_{1_{\mathrm{Hz}}}[\mathrm{m}]$ \\
\hline Igneous rock & $\sim 10^{-4}$ & $5.033 \times 10^{5}$ & $1.591 \times 10^{5}$ & $5.033 \times 10^{4}$ \\
Metamorphous/Limestone & $\sim 10^{-3}$ & $1.591 \times 10^{5}$ & $5.033 \times 10^{4}$ & $1.591 \times 10^{4}$ \\
Sediment & $\sim 0.01$ & $5.033 \times 10^{4}$ & $1.591 \times 10^{4}$ & $5.033 \times 10^{3}$ \\
Sea water & $\sim 5$ & $2.250 \times 10^{3}$ & 711.76 & 225.08 \\
Graphite & $\sim 100$ & 503.29 & 159.15 & 50.33 \\
\hline
\end{tabular}

$\delta$ of an electromagnetic wave at very low frequencies can be written

$$
\delta=\sqrt{\frac{2}{\mu \cdot \sigma \cdot \omega}},
$$

where $\mu$ is the magnetic permeability. For the conductivity $\sigma$ an average value of $\left\langle\sigma>=10^{-3} \mathrm{~S} / \mathrm{m}\right.$ is assumed and a frequency $\omega=2 \pi f, f=30 \mathrm{mHz}$ is considered. This results in

$$
\begin{aligned}
\delta & =\sqrt{\frac{2}{4 \cdot \pi \times 10^{-7} \cdot 1 \times 10^{-3} \cdot 2 \cdot \pi \cdot 30 \times 10^{-3}}} \\
& =9.1888 \times 10^{4} \mathrm{~m} \sim 100 \mathrm{~km}
\end{aligned}
$$

For a plane wave the magnetic field strength decreases exponential in propagation direction.

$\boldsymbol{H}(x)=\boldsymbol{H}_{0} \cdot e^{-\frac{x}{\delta}}$,

which results in

$\boldsymbol{H}_{0}=\boldsymbol{H}(x) \cdot e^{\frac{x}{\delta}}=0.157 \cdot e^{\frac{153000}{9.1888 \cdot 10^{4}}}=0.831 \mathrm{nT}$.

The magnetic field strength variation in the earthquake focus region is assumed to be $\delta Z_{\text {focus }}=0.831 \mathrm{nT}$, see also Molchanov and Hayakawa (1998) and Kopytenko et al. (2004) and detailed studies were performed in Malvezzi (2003).

\section{Conclusion and outlook}

ULF magnetic field observations are a promising technique of analysis associated to anomalies before earthquakes. The ULF disturbances related to earthquakes are generally weak and sophisticated signal processing methods and a lot of experience is required to evaluate the source of ULF emission (Harada et al., 2004; Hattori and Hayakawa, 2007). The three main sources of emission are geomagnetic influences, man made noise and seismogenic ULF emission. We observed the wave intensities of both magnetic field components horizontal $H$ and vertical $Z$ and the polarization ratio $R$ for a long period from June to August 2004 and emphasised on the results from the observatory Castello Tesino closest to the Bovec earthquake. High wave intensities during geomagnetic active time periods can be observed for all SEGMA stations. The SEGMA multipoint chain gives the opportunity to compare the measurements from different stations, e.g. CST and two remote stations NCK and RNC. Using a simple planar wave model we estimated the magnetic field amplitude possibly generated in the earthquake focus region. Assuming the model with the measured vertical intensity of $\delta Z_{\max }=0.157 \mathrm{nT}$ at Castello Tesino the estimated magnetic intensity in the focus region of the Bovec earthquake is about $\delta Z_{\text {focus }}=0.831 \mathrm{nT}$. The observatory is located at $153 \mathrm{~km}$ distance to the epicenter, the average electrical conductivity $<\sigma>=10^{-3} \mathrm{~S} / \mathrm{m}$. The polarization ratio $R$ which is the vertical to horizontal field power in the ULF frequency band from $10-50 \mathrm{mHz}$ increased the first time about three weeks before the earthquake and the second time about one week before the earthquake staying high until a few days after the Bovec seismic event. We found a significant temporal dependence and a spatial dependence of polarization. A concise increase was observed at Castello Tesino station. The polarization ratio decreased depending on the distance between the station and the earthquake epicenter, taking into account the stations Nagycenk and Ranchio. All three stations showed coherent increased ratios several days before the event.

Future activities are to improve the model taking into consideration inhomogeneous crust media. The analysed frequency range could be extended up to $64 \mathrm{~Hz}$. Further ULF/ELF combined electric and magnetic field data could be analysed. As proposed by many authors sophisticated signal analysis methods, see also Nenovski et al. (2007) could be applied to discriminate geomagnetic effects, manmade noise and seismomagnetic influence. The SEGMA multipoint chain could be extended to perform magnetic field analysis recorded in European earthquake regions. Joint ground based and satellite data analysis using results from DEMETER space mission are planned.

Edited by: M. Contadakis

Reviewed by: two anonymous referees

\section{References}

Biagi, P. F., Castellana, L., Maggipinto, T., Maggipinto, G., Minafra, G., Ermini, A., Capozzi, V., Perna, G., Solovieva, M., Rozhnoi, A., Molchanov, O. A., and Hayakawa, M.: Decrease 
in the electric intensity of vlf/lf radio signals and possible connections, Nat. Hazards Earth Syst. Sci., 7, 423-430, 2007, http://www.nat-hazards-earth-syst-sci.net/7/423/2007/.

Fraser-Smith, A. C., Bernardi, A., McGill, A., Ladd, M. E., Helliwell, R., and Villard, J. O.: Low-frequency magnetic field measurements near the epicenter of the ms 7.1 loma prieta earthquake, Geophys. Res. Lett., 17, 1465-1468, 1990.

Gladychev, V., Baransky, L., Schekotov, A., Fedorov, E., Pokhotelov, O., Andreevsky, S., Rozhnoi, A., Khabazin, Y., Belyaev, G., Gorbatikov, A., Gordeev, E., Chebrov, V., Sinitsin, V., Lutikov, A., Yunga, S., Kosarev, G., Surkov, V., Molchanov, O., Hayakawa, M., Uyeda, S., Nagao, T., Hattori, K., and Noda, Y.: Study of electromagnetic emissions associated with seismic activity in kamchatka region, Nat. Hazards Earth Syst. Sci., 1, 127-136, 2001, http://www.nat-hazards-earth-syst-sci.net/1/127/2001/.

Gokhberg, M. B., Vitali, B., and Morgounov, A.: Anomalous electromagnetic emission sources, in: Earthquake prediction seismoelectromagnetic phenomena, Moscow, 31, 1995.

Harada, M., Hattori, H., and Isezaki, N.: Transfer function approach to signal discrimination of ulf geomagnetic data, Elsevier, Phys. Chem. Earth, 29, 409-417, 2004.

Hattori, K. and Hayakawa, M.: Recent progress and state of the art seismo-electromagnetics, IEEJ Trans. No. 1., 127, 3, 2007.

Hayakawa, M. and Fujinawa, Y.: Electromagnetic phenomena related to earthquake prediction., Tokyo, 677 pp., 1994.

Hayakawa, M., Kawate, R., Molchanov, O., and Yumoto, K.: Results of ultra-low-frequency magnetic field measurements during the guam earthquake of 8 August 1993, Geophys. Res. Lett., 23, 241-244, 1996.

Hayakawa, M., Hattori, K., and Ohta, K.: Monitoring of ulf (ultralow-frequency) geomagnetic variations associated with earthquakes, sensors, Sensors, 7, 1108-1122, 2007.

ISGI, I. S. o. G. I.: Geomagnetic indices, ISGI (International Service of Geomagnetic Indices), http://isgi.cetp.ipsl.fr/, 2007.

Kopytenko, Y., Ismagilov, V., Hayakawa, M., Smirnova, N., Trojan, V., and Peterson, T.: Investigation of the ulf electromagnetic phenomena related to earthquakes: Contemporary achievements and the perspectives, Ann. Geophys., 44, 325-334, 2004, http://www.ann-geophys.net/44/325/2004/.

Magnes, W.: Ground-station magnetometer network chimag in the frame of the chinese meridian project, TU-Graz, Graz, 167 pp., 1999.

Malvezzi, V.: A physical model of pre-earthquake electromagnetic emissions propagating in layered lithospheric and atmospheric media, Tesi di Dottorato in Fisica, XVI Ciclo, Università degli Studi di Roma Tor Vergata, Rome, 322 pp., 2003.

Masci, F., Palangio, P., Di Persio, M., and C. Di Lorenzo, C.: The development of the ingv tectonomagnetic network in the frame of the mem project, Nat. Hazards Earth Syst. Sci., 7, 473-478, 2007 ,

http://www.nat-hazards-earth-syst-sci.net/7/473/2007/.

Molchanov, O. and Hayakawa, M.: On the generation mechanism of ulf seismogenic electromagnetic emissions, Phys. of the Earth and Planet. Int., 105,0201-210, 1998.
Molchanov, O., Kulchitsky, A., and Hayakawa, M.: Inductive seismo-electromagnetic effect in relation to seismogenic ulf emission, Nat. Hazards Earth Syst. Sci., 1, 61-67, 2001, http://www.nat-hazards-earth-syst-sci.net/1/61/2001/.

Molchanov, O., Schekotov, A., Fedorov, E., Belyaev, G., and Gordeev, E.: Preseismic ulf electromagnetic effect from observation at kamchatka, Nat. Hazards Earth Syst. Sci., 3, 203-209, 2003 ,

http://www.nat-hazards-earth-syst-sci.net/3/203/2003/.

Molchanov, O., Fedorov, E., Schekotov, A., Gordeev, E., Chebrov, V., Surkov, V., Rozhnoi, A., Andreevsky, S., Iudin, D., Yunga, S., Lutikov, A., Hayakawa, M., and Biagi, P.: Lithosphereatmosphere-ionosphere coupling as governing mechanism for preseismic short-term events in atmosphere and ionosphere, Nat. Hazards Earth Syst. Sci., 4, 457-467, 2004a,

http://www.nat-hazards-earth-syst-sci.net/4/457/2004/.

Molchanov, O., Schekotov, A., Fedorov, E., Belyaev, G., Solovieva, M., and Hayakawa, M.: Preseismic ulf effect and possible interpretation, Ann. Geophys., 47, 119-131, 2004b,

http://www.ann-geophys.net/47/119/2004/.

Nenovski, P., Blagoeva, I., Vellante, M., Villante, U., Schwingenschuh, K., Boudjada, M., and Wesztergom, V.: Identification of sources of geomagnetic variations using detrended fluctuation analysis (dfa), WDS'07 Proceedings of Contributed Papers, Part II, 7, 2007.

Parrot, M., Berthelier, J. J., Lebreton, J. P., Sauvaud, J. A., Santolı'k, O., and Blecki, J.: Examples of unusual ionospheric observations made by the demeter satellite over seismic regions, Phys. Chem. Earth, 31, 486-495, 2006.

Prattes, G.: Signal analysis of ground-based seismo-magnetic ulf events in the frame of the segma and demeter projects, Diploma, Institute of Broadband Communication, University of Technology, Graz, 125 pp., 2007.

Schwingenshuh, K., Magnes, W., Zhang, T. L., Berghofer, G., Koren, W., Riedler, W., Mocnik, K., H., O., Stachel, M., Scherr, A., Zhao, H., Zhou, G. C., Wang, D. J., Chen, S. W., Le, G., Means, J., Greer, W., Pierce, D., Snare, B., and C.T., R.: Low latitude magnetometer chain in china in the frame of the meridian project Proceedings of the DO.1 Symposium of COSPAR Scientific Commission D, 25, 3, 2000.

Sorokin, V., Fedorov, E., Schekotov, A., Molchanov, O., and Hayakawa, M.: Depression of the ulf geomagnetic pulsation related to ionospheric irregularities, Geophys. Res. Lett., 47, 191198, 2004.

Vellante, M., Luhr, H., Zhang, T. L., Wesztergom, V., Villante, U., De Lauretis, M., Piancatelli, A., Rother, M., Schwingenschuh, K., Koren, W., and Magnes, W.: Ground/satellite signatures of field line resonance: A test of theoretical predictions, J. Geophys. Res.-Space Phys., 109, A06210, doi:10.1029/2004JA010392, 2004.

Villante, U., Vellante, M., Piancatelli, A., Di Cienzo, A., Zhang, T. L., Magnes, W., Wesztergom, V., and Meloni, A.: Some aspects of man-made contamination on ulf measurements, Ann. Geophys., 22, 1335-1345, 2004,

http://www.ann-geophys.net/22/1335/2004/.

ZAMG: Erdbeben, www.Zamg.Ac.At/erdbeben/, last visited 2007. 